\title{
Different Mechanisms Underlying the Antiepileptic and Antiparkinsonian Effects of Zonisamide
}

\author{
Motohiro Okada ${ }^{1}$ and Sunao Kaneko ${ }^{2}$ \\ ${ }^{1}$ Department of psychiatry, \\ Brain science and animal model research center (BSAM), \\ Graduate school of medicine, Mie University \\ ${ }^{2}$ Department of neuropsychiatry, Graduate school of medicine, Hirosaki University,
}

Japan

\section{Introduction}

Zonisamide (ZNS, 3-sulfamoylmethyl-1,2-benzisoxazole) was developed by Dainippon Pharma (Osaka, Japan: currently Dainippon Sumitomo Pharma) and is currently used as an antiepileptic drug (AED) in Japan, South Korea, USA and Europe (Seino, 2004; Seino \& Leppik, 2007). Indeed, the wide antiepileptic spectrum of ZNS has been established (Brodie, 2004; Karceski et al., 2005; Seino, 2004; Seino \& Leppik, 2007; Willmore, 2004). Several clinical studies have also reported the wide clinical spectrum of ZNS against psychiatric and non-epileptic neurological disorders, including mood disorders (Ghaemi et al., 2008; Ghaemi et al., 2006; Kanba et al., 1994; McElroy et al., 2005), essential tremors (Bermejo, 2007), and its protective effects against ischemic cerebral damage (Willmore, 2004) and Parkinson's disease (Murata, 2004; Murata et al., 2007). In Japan, ZNS was approved for Parkinson's disease in 2009 by the Ministry of Health, Labor and Welfare. In this chapter, we review the dose-dependent effects of ZNS on neurotransmission and differences in the mechanisms underlying its antiepileptic and antiparkinsonian effects.

\section{Antiepileptic mechanisms of ZNS}

The major mechanism underlying the antiepileptic effects of ZNS (Rogawski \& Porter, 1990) is inhibition of the voltage-gated $\mathrm{Na}^{+}$channel (Rock et al., 1989; Schauf, 1987). However, subsequent pharmacological studies have demonstrated that the target molecules of ZNS include T-type voltage-sensitive $\mathrm{Ca}^{2+}$ channel (Kito et al., 1996; Suzuki et al., 1992), $\mathrm{Ca}^{2+}$ induced $\mathrm{Ca}^{2+}$ releasing system (CICR) (Yamamura et al., 2009b; Yoshida et al., 2005), carbonic anhydrase (Yamamura et al., 2009a), redox (Tokumaru et al., 2000; Ueda et al., 2005; Ueda et al., 2003), neuronal depolarization-induced glutamate release (Okada et al., 1998; Yoshida et al., 2005), enhancement of release of inhibitory neurotransmitters, e.g., GABA (Yoshida et al., 2005), dopamine and serotonin (Murakami et al., 2001; Okada et al., 1999; Okada et al., 1992; Okada et al., 1995) and lack of affinity to $\mathrm{GABA}_{\mathrm{A}}$ receptor (Rock et al., 1989).

With regard to its antiparkinsonian action, ZNS enhances both the turnover and release of dopamine, and inhibits MAO-B activity and dopaminergic oxidative stress (Asanuma et al., 
2008; Komatsu et al., 2000; Leppik, 2004; Mori et al., 1998; Murata, 2004; Okada et al., 1992; Okada et al., 1995; Ueda et al., 2005). While the typical dose of ZNS is 300 to $600 \mathrm{mg} /$ day for patients with epilepsy (Seino et al., 1988), a significant improvement in motor symptoms is reported in patients of Parkinson's disease treated with only 25 to $100 \mathrm{mg} /$ day of ZNS (Murata, 2004; Murata et al., 2007).

Ion channel blockade

- Voltage-gated $\mathrm{Na}^{+}$channel

- Enhancement of $\mathrm{Na}^{+}$channel inactivation

- Inhibition of seizure-related repetitive neural firing

- Enhancement of N-typerstage

- Inhibition of T-type $\mathrm{Ca}^{2+}$ channel

- Inhibition of L-type $\mathrm{Ca}^{2+}$ channel

- Inhibition of $\mathrm{N}$-type and $\mathrm{P}$-type $\mathrm{Ca}^{2+}$ channel during hyperexcitable stage

- Enhancement of $\mathrm{N}$-type and $\mathrm{P}$-type $\mathrm{Ca}^{2+}$ channel during resting stage

- $\mathrm{Ca}^{2+}$-induced $\mathrm{Ca}^{2+}$ releasing (CICR) channel

- Enhancement of IP3R during resting stage without affecting RyR activity

- Inhibition of IP3R and RyR during hyperexcitable stage

Neurotransmitter modulation

- Neuronal exocytosis

- Enhancement of syntaxin/N-type $\mathrm{Ca}^{2+}$ channel during resting stage

- Inhibition of synaptobrevin/P-type $\mathrm{Ca}^{2+}$ channel during hyperexcitable stage

- Glutamatergic system

- Inhibition of glutamate release during hyperexcitable stage

- Enhancement of glutamate transporter expression

- GABAergic system

- No affinity for GABA receptors

- Binding allosterically to GABA receptors

- Downregulation of GABA transporter

- Monoaminergic system

- Enhancement of dopamine and serotonin releases within therapeutic range

- Inhibition of dopamine and serotonin releases at supratherapeutic range

- Inhibition of MOA-B

- Enhancement of monoamine synthesis (enhancement of turnover)

Other systems

- Carbonic anhydrase

- Inhibition of cytosolic, mitochondrial and plasma membrane binding subtypes

- Prevention of conversion excitatory features of $\mathrm{GABA}_{\mathrm{A}}$ receptor induced by epileptic hyperexcitability

- Redoxsystem

- Scavenging against free radical associated with cytosolic and plasma membrance in epileptogenic foci

- Inhibition of DNA damage under oxidative stress

- Suppression of lipid oxidation

Table 1. Possible antiepileptic mechanism of ZNS 


\subsection{Effects of ZNS on ion channels}

Preclinical studies suggested that ZNS inhibits the propagation of epileptic hyperexcitability through neuronal membrane stabilization and prevention of synchronization of firing (Macdonald, 2002; Rock et al., 1989; Rogawski \& Porter, 1990; Schauf, 1987). Ample evidence indicates that the modulation of activities of several types of ion channels is the major mechanism of the antiepileptic effect of ZNS (Macdonald, 2002; Rogawski \& Porter, 1990; Seino \& Leppik, 2007).

\subsubsection{Effects of ZNS on voltage-gated $\mathrm{Na}^{+}$channel}

The antiepileptic effects of ZNS on partial seizures are due to inhibition of voltage-gated $\mathrm{Na}^{+}$channels. In in vitro electrophysiological studies, ZNS reduced sustained repetitive firing by inhibiting voltage-gated $\mathrm{Na}^{+}$channels (Rock et al., 1989; Schauf, 1987). These inhibitory effects of ZNS probably increase the threshold of neuronal action potentials and lead a shift in the steady-state fast inactivation threshold of voltage-gated $\mathrm{Na}^{+}$channels (Macdonald, 2002; Rogawski \& Porter, 1990; Seino \& Leppik, 2007). The inhibitory effects of ZNS on $\mathrm{Na}^{+}$currents is probably induced by preferential binding to inactive voltage-gated $\mathrm{Na}^{+}$channels that produces use- and voltage-dependent blockade and slows the rate of recovery from inactivation (Macdonald, 2002)

\subsubsection{Effects of ZNS on voltage-sensitive $\mathrm{Ca}^{2+}$ channel}

The role of voltage-sensitive $\mathrm{Ca}^{2+}$ channel in epilepsy is entirely consistent with its ability to orchestrate numerous neuronal events thought to be altered in seizures such as neurotransmitter release, dendritic physiology, gene expression and notably epileptic seizure-induced neuronal apoptosis (Zhang et al., 2000). ZNS inhibits high-threshold voltage-sensitive $\mathrm{Ca}^{2+}$ channel (L-type $\mathrm{Ca}^{2+}$ channel)(Kito et al., 1996; Rossier et al., 1996 ). ZNS also inhibits low-threshold voltage-sensitive $\mathrm{Ca}^{2+}$ channel (T-type $\mathrm{Ca}^{2+}$ channel) in a concentration-dependent manner (Kito et al., 1996; Rossier et al., 1996; Suzuki et al., 1992). The T-type $\mathrm{Ca}^{2+}$ channel is activated by small depolarization of the neuronal plasma membrane; and the resulting $\mathrm{Ca}^{2+}$ influx generates low threshold spikes that can trigger a burst of action potentials mediated by $\mathrm{Na}^{+}$channels (Perez-Reyes, 2003). Therefore, antiepileptic actions of ZNS against childhood absence epilepsy and catastrophic childhood epilepsy are mediated through its inhibitory effects on T-type $\mathrm{Ca}^{2+}$ channel (Rogawski \& Loscher, 2004a, b; White, 1999).

\subsubsection{Effects of ZNS on CICR}

The intraneuronal $\mathrm{Ca}^{2+}$ mobilization comprises both $\mathrm{Ca}^{2+}$ influx via voltage-sensitive $\mathrm{Ca}^{2+}$ channels and ligand-gated ion channels, as well as output from intracellular $\mathrm{Ca}^{2+}$ stores associated with the endoplasmic reticulum, namely the CICR, which is comprised of the ryanodine receptor (RyR) and inositol 1,4,5-trisphosphate receptor (IP3R) (Berridge, 1998). Several studies have indicated recently that functional abnormalities of CICR contribute to the rise in intraneuronal $\mathrm{Ca}^{2+}$ concentration associated with epileptic seizures (Matsumoto \& Nagata, 1999; Matsumoto et al., 1996; Mori et al., 2005). Transient up-regulation of both cFos and Ryr-3 gene expression was observed in the hippocampus of the kainate-induced epilepsy model (Mori et al., 2005). Antagonists of both RyR and IP3R had no effect on the induction or persistence of epileptiform discharges, but both types of antagonists prevent seizure-induced neuronal death (Pal et al., 2001; Pelletier et al., 1999). During resting stage, 
ZNS activates IP3R but has no effect on RyR (Yamamura et al., 2009c; Yoshida et al., 2005). Contrary to the resting stage, during neuronal hyperexcitability, ZNS inhibits the activities of both IP3R and RyR (Yamamura et al., 2009c; Yoshida et al., 2005). These actions of ZNS are similar to other antiepileptic drug, topiramate (Okada et al., 2005).

\subsection{Effects of ZNS on other neuromodulating systems}

\subsubsection{Effects of ZNS on the redox system}

Current research associates free radical damage with epilepsy (Komatsu et al 1995; Sudha et al 2001), and the use of antioxidants early in the treatment of seizure-related neuronal injury is an attractive strategy, since epileptic seizures cause neuronal cell damage through the production of free radicals (Komatsu et al., 2000; Sudha et al., 2001). ZNS protects neurons against free-radical damage by scavenging the hydroxyl and nitric oxide radicals and such action is dose-dependent (Leppik, 2004; Mori et al., 1998; Noda et al., 1999). Especially, ZNS provides scavenging effects against cytosolic and plasma membrane-targeting free radicals in epileptogenic foci (Komatsu et al., 2000; Tokumaru et al., 2000; Ueda et al., 2005; Ueda et al., 2003). The radical scavenging properties operate in not only the ZNS-related antiepileptic activity but also its neuroprotective action against hypoxic/ischemic brain damage (Hayakawa et al., 1994; Owen et al., 1997).

\subsubsection{Effects of ZNS on carbonic anhydrase}

It was initially thought that the inhibitory effects of ZNS on carbonic anhydrase do not contribute to the antiepileptic action of ZNS, since the $\mathrm{IC}_{50}$ value of ZNS is 188 times less potent than that of acetazolamide (Masuda \& Karasawa, 1993). However, subsequent studies demonstrated that different affinities to carbonic anhydrase subtypes (Casini et al., 2003; Supuran, 2008). The Ki values for ZNS on cytosolic hCAII (35 nM), mitochondrial hCAV (20 nM) and plasma membrane binding hCAIX (5.1 nM) (Casini et al., 2003; Supuran, 2008) are lower than the therapeutic-relevant plasma concentrations of ZNS (Okada et al., 1999; Okada et al., 1995; Yamamura et al., 2009a). Activation of $\mathrm{GABA}_{\mathrm{A}}$ receptor opens its $\mathrm{Cl}^{-}$channel, which is permeable to both $\mathrm{HCO}_{3}{ }^{-}$efflux and $\mathrm{Cl}^{-}$influx (Staley et al., 1995). Under physiological conditions, the hyperpolarizing action of the $\mathrm{Cl}^{-}$influx abolishes the depolarizing effect of $\mathrm{HCO}_{3}{ }^{-}$efflux (Staley et al., 1995). In contrast to physiological conditions, continuous neuronal hyperactivation, e.g., epileptic seizure, results in an increase in intraneuronal $\mathrm{Cl}^{-}$concentration (Ge et al., 2006; Ge et al., 2007; Okada et al., 2003). A rise in $\mathrm{Cl}^{-}$concentration in the synaptic active zone stimulates $\mathrm{GABA}_{\mathrm{A}}$ receptor to produce depolarizing action (Ge et al., 2006; Ge et al., 2007). Inhibition of carbonic anhydrase reduces intraneuronal $\mathrm{HCO}_{3}{ }^{-}$concentration with enhancement of $\mathrm{Na}^{+}$ independent $\mathrm{Cl}^{-} / \mathrm{HCO}_{3}{ }^{-}$exchange (Leniger et al., 2004). Thus, ZNS prevents the epileptic hyperexcitability-induced conversion of $\mathrm{GABA}_{\mathrm{A}}$ receptor activity from inhibitory to excitatory activity (Yamamura et al., 2009a).

\subsection{Effects of ZNS on neurotransmitter system}

The generation of epileptic seizures could be due to a relative imbalance between excitatory and inhibitory neurotransmission, resulting in increased neuronal excitability and abnormally frequent patterns of discharge (Hirose et al., 2000; Okada et al., 2002). Glutamate is one of the main excitatory neurotransmitters, and excessive release of glutamate seems to precipitate seizures in epileptic patients and in animal models of epilepsy (Hirose et al., 
2000; Okada et al., 2002). In contrast to glutamate, various other neurotransmitters, e.g., GABA, dopamine, serotonin and acetylcholine, are involve in the regulation of inhibitory transmission (Hirose et al., 2000; Okada et al., 2002; Okada et al., 2010).

\subsubsection{Effects of ZNS on glutamatergic system}

Both systemic administration of therapeutically-relevant dose and local perfusion of therapeutically-relevant concentration of ZNS reduced depolarization induced glutamate release in the hippocampus and frontal cortex (Okada et al., 1998; Yamamura et al., 2009a; Yamamura et al., 2009b; Yamamura et al., 2009c; Yoshida et al., 2005). It has been demonstrated that continuous stimulation induced by glutamate release has several components: (1) a $\mathrm{Ca}^{2+}$-dependent initial rise, which is neuronal activity-independent, (2) this initial rise $\mathrm{s}$ followed by a series of $\mathrm{Ca}^{2+}$-dependent phasic rises associated with neuronal activity, and (3) a small overflow of glutamate that persists in a $\mathrm{Ca}^{2+}$-independent manner (Obrenovitch et al., 1993; Obrenovitch et al., 1996; Okada et al., 1998; Zilkha et al., 1995). Especially, the third component, which is $\mathrm{Ca}^{2+}$ independent and neuronal activity independent glutamate release, is probably spreading depression induced release (Okada et al., 1998). Therapeutically relevant concentrations of ZNS inhibit these three types of glutamate effects in the hippocampus (Okada et al., 1998).

\subsubsection{Effects of ZNS on GABAergic system}

ZNS has dual action against GABAergic transmission; enhancement of GABA release and protection against conversion $\mathrm{GABA}_{\mathrm{A}}$ receptor activity from inhibitory to excitatory action. ZNS tends to enhance the inhibitory function of $\mathrm{GABA}_{\mathrm{A}}$ receptor through interaction at allosteric or other binding sites (Mimaki et al., 1988) and GABAergic transmission via downregulation of GABA transporter (Ueda et al., 2003). Inhibition of carbonic anhydrase reduces intraneuronal $\mathrm{HCO}_{3}{ }^{-}$concentration with enhancement of $\mathrm{Na}^{+}$-independent $\mathrm{Cl}^{-} / \mathrm{HCO}_{3}{ }^{-}$ exchange (Leniger et al., 2004). Although there is no direct evidence that it activates $\mathrm{GABA}_{\mathrm{A}}$ receptor-associated neuronal events, ZNS enhances the $\mathrm{Cl}^{-}$currents associated with $\mathrm{GABA}_{\mathrm{A}}$ receptor (Mimaki et al., 1988). These actions of ZNS are possibly modulated by inhibition of carbonic anhydrase activity similar to topiramate (Sills et al., 2000). Both systemic administration of therapeutically-relevant dose and local perfusion of therapeuticallyrelevant concentration of ZNS increased and decreased the basal and depolarizationinduced releases of GABA in the hippocampus and frontal cortex, respectively (Okada et al., 1998; Yamamura et al., 2009a; Yamamura et al., 2009b; Yamamura et al., 2009c; Yoshida et al., 2005). Furthermore, the inhibitory interneurons release GABA (Hirose et al., 2000; Okada et al., 2002; Staley et al., 1995; Zhu et al., 2008).

\subsubsection{Effects of ZNS on monoamine release}

Systemic administration of ZNS affects monoamine release in the hippocampus, frontal cortex and striatum in a biphasic dose-dependent manner (Kawata et al., 1999; Murakami et al., 2001; Okada et al., 1999; Okada et al., 1992; Okada et al., 1995; Okada et al., 2002). At therapeutically-relevant dose, ZNS increases extracellular levels of monoamines, whereas ZNS at supra-therapeutic dose decreases monoamine release (Kawata et al., 1999; Murakami et al., 2001; Okada et al., 1999; Okada et al., 1992; Okada et al., 1995; Okada et al., 2002). Similar to its effect on the release of monoamines, both acute and chronic administration of therapeutically-relevant doses of ZNS enhance the turnover of dopamine and serotonin (i.e., 
monoamine synthesis) (Okada et al., 1999; Okada et al., 1992; Okada et al., 1995). In addition, ZNS inhibits monoamine oxidase activity. These stimulatory effects of ZNS on monoaminergic transmission, via enhancement of monoamine synthesis and release with inhibition of monoamine degradation, are observed after chronic administration (Okada et al., 1999; Okada et al., 1992; Okada et al., 1995).

\title{
3. Antiparkinsonian mechanisms of ZNS
}

In an open clinical trial of a combination of ZNS (50-200 mg/day) with antiparkinsonian drugs showed lessening of symptoms, wearing off of Parkinson's disease, and more than $30 \%$ improvement of total score of the Unified Parkinson's Disease Rating Score up to 3 years (Murata, 2004; Murata et al., 2001). The addition of ZNS to L-DOPA treatment in patients experiencing "wearing-off" fluctuations resulted in lessening of motor fluctuation and significant improvement of the duration, severity, and activities of daily living in "off " time and the score of motor examination. A more recent double blind controlled study from Japan demonstrated that the combination of lower than antiepileptically-relevant dose of ZNS (25-100 mg/day) and L-DOPA improved all cardinal symptoms of Parkinson's disease (Murata et al., 2007). Based on these clinical evidences, ZNS was released for use in Japan in March 2009 as a novel antiparkinsonian agent.

In a series of studies, we have reported a dose-dependent biphasic action for ZNS on striatal dopaminergic system, e.g., ZNS at $25-50 \mathrm{mg} / \mathrm{kg}$ (i.p.) increased whereas at $100 \mathrm{mg} / \mathrm{kg}$ (i.p.) it decreased striatal dopamine release. However, ZNS at lower than antiepilepticallyrelevant dose of ZNS failed to modulate striatal dopaminergic transmission (Murakami et al., 2001; Okada et al., 1999; Okada et al., 1992; Okada et al., 1995; Yamamura et al., 2009b). These results suggest possible differences in the mechanisms of the antiepileptic and antiparkinsonian actions of ZNS. In this regard, the mechanism of the antiparkinsonian action of ZNS remains poorly understood.

\author{
Ion channel blockade \\ - Inhibition of T-type voltage-sensitive $\mathrm{Ca}^{2+}$ channel \\ - Inhibition of dopamine-quinone formation \\ - Enhancement of glutathione synthesis \\ - Enhancement of transmission in indirect pathway
}

Table 2. Possible antiparkinsonian mechanism of ZNS

\subsection{Inhibition of dopamine quinone formation}

Under normal conditions, dopamine is stable in the synaptic vesicle; however, administration of L-DOPA to patients with Parkinson's disease damages the dopaminergic neuronal system (Sulzer et al., 2000). In patients with Parkinson's disease treated with LDOPA, a large amount of dopamine remains in the cytosol away from the synaptic vesicle, since the damaged dopaminergic system has only a small dopamine pool for storage (Asanuma et al., 2008; Asanuma et al., 2003; Ogawa et al., 2005; Sulzer et al., 2000).

Despite the beneficial effects of L-DOPA, the toxicity of excess L-DOPA and dopamine has been well documented in many in vitro and in vivo animal studies using parkinsonian models (Asanuma et al., 2008; Asanuma et al., 2003; Ogawa et al., 2005; Sulzer et al., 2000). 
Free excess dopamine is easily metabolized via type-B monoamine oxidase (MAO-B) or by auto-oxidation to produce cytotoxic reactive oxygen species (ROS), and then forms neuromelanin (Sulzer et al., 2000). In the oxidation of dopamine by MAO-B, dopamine is converted to DOPAC to generate general ROS hydrogen peroxide (Sulzer et al., 2000). Conversely, non-enzymatic and spontaneous auto-oxidation of L-DOPA and dopamine produces superoxide and reactive quinones, dopamine-quinone and DOPA-quinone, (Asanuma et al., 2003; Ogawa et al., 2005; Sulzer et al., 2000; Tse et al., 1976). The highly reactive dopamine-quinone or DOPA-quinone itself exerts predominant cytotoxicity in dopaminergic neurons and surrounding neurons, since these quinones are generated from free cytosolic dopamine away from the synaptic vesicle or from L-DOPA (Sulzer et al., 2000).

ZNS prevents dopamine-quinone formation induced by excess amount of cytosolic dopamine outside the synaptic vesicles (Asanuma et al., 2008).

\subsection{Enhancement of glial glutathione synthesis}

Glutathione acts as an antioxidant against ROS-induced neurodegeneration. Astrocytes, but not neurons, express cystine/glutamate exchange transporter, which takes up cystine, reduces it to cysteine, and consequently supplies cysteine, the substrate for glutathione synthesis, in neurons. Glutathione synthesis in neurons is dependent on the expression of the cystine/glutamate exchange transporter on astrocytes (Shih et al., 2006; Wang \& Cynader, 2000). Other studies demonstrated that glutathione and its synthesis-related molecules provide protection for astrocytes against age-dependent nigrostriatal dopaminergic neuro-degeneration (Chinta et al., 2007; Solano et al., 2008). ZNS markedly increased glutathione levels by enhancing the astroglial cystine/glutamate exchange transporter and astroglial proliferation via S100 $\beta$ production or secretion. ZNS acts as a neuroprotectant against oxidative stress and progressive dopaminergic neurodegeneration (Asanuma et al., 2010).

\subsection{Enhancement of transmission striato-pallidal indirect pathway}

Parkinson's disease is characterized neuropathologically by a relative and selective loss of dopaminergic projection neurons within the substantia nigra pars compacta $(\mathrm{SNc})$, and the formation of cytoplasmic inclusions within many surviving neurons (Gibb, 1991). The reduced population of dopaminergic neurons in $\mathrm{SNc}$ leads to the development of classical symptoms of Parkinson's disease through functional abnormalities in striatal output pathways, which are composed of direct and indirect pathways (Hauber, 1998). In the rat brain, the direct pathway is composed of striatal GABAergic neurons, which project to the substantia nigra pars reticulata $(\mathrm{SNr})$, a region under dopamine $\mathrm{D}_{1}$ receptor-mediated stimulatory regulation (Hauber, 1998). The indirect pathway comprises the striatal GABAergic neurons that project to the globus pallidus (GP) and are under dopamine $\mathrm{D}_{2}$ receptor-mediated inhibitory regulation, the pallidal GABAergic neurons that project to the nucleus subthalamicus (STN) and the subthalamic glutamatergic neurons that project to GP and SNr (Hauber, 1998). Indeed, depletion of dopaminergic transmission produces overinhibition of pallido-subthalamic GABAergic and disinhibition of subthalamonigral glutamatergic projections in the indirect pathway (DeLong, 1990; Hauber, 1998). Enkephalin is colocalized and acts as cotransmitter with GABA in striatal neurons that project to GP; however, enkephalin reduces the GABAergic inhibition in the indirect pathway via 
inhibition of GABA release (Maneuf et al., 1994). Based on these effects, the $\delta$ opioid receptor and its endogenous agonist enkephalin have been proposed as a suitable target in the symptomatic therapy of Parkinson's disease (Hille et al., 2001; Maneuf et al., 1994).

Local administration of antiepileptic-relevant concentrations of ZNS in the striatum increases dopamine release, whereas the use of antiparkinsonian-relevant concentration of ZNS does not affect striatal dopamine release (Yamamura et al., 2009b). Local administration of both antiparkinsonian- and antiepileptic-relevant concentrations of ZNS in the striatum reduces the extracellular levels of GABA in STN and glutamate in SNr, but decreases extracellular levels of GABA in GP without affecting their level in $\mathrm{SNr}$ (Yamamura et al., 2009b). These concentration-dependent effects of ZNS on extracellular neurotransmitter levels are independent of dopamine and $\delta 2$ receptors; however, blockade of $\delta 1$ receptor inhibited the effects of ZNS (Yamamura et al., 2009b). Activation of $\delta 1$ receptor enhances the effects of ZNS on neurotransmitter level. Based on these results, we suggest that ZNS does not affect the direct pathway but inhibits the $\delta 1$ receptor-mediated indirect pathway.

\section{Conclusion}

It has been well established that ZNS is the first line antiepileptic drug in the treatment of partial, absence and generalized epilepsies. In addition, ZNS is a potentially useful agent in the treatment of Parkinson's disease. Its antiepileptic potential has been demonstrated in several clinical studies and meta-analysis studies; however, the antiparkinsonian potential has been demonstrated in only one randomized, placebo-controlled study.

The mechanisms of the antiepileptic action of ZNS have been investigated through various basic experiments, whereas the antiparkinsonian mechanisms remain to be clarified. Interestingly, the dose of ZNS used for the treatment of patients with Parkinson's disease is lower than its therapeutic range against epilepsy. To our knowledge, the pharmacological profile within the antiparkinsonian dose has demonstrated only an increase in glutathione synthesis and enhancement of transmission through the indirect pathway. Enhancement of the indirect pathway is probably involved in the improvement of symptoms of Parkinson's disease. In contrast, activation of glutathione synthesis prevents the progression of Parkinson's disease rather than improves symptoms. Therefore, ZNS likely improves longterm prognosis. More information is required to clarify the effects of ZNS on long-term prognosis of patients with Parkinson's disease (the long-term efficacy of ZNS). Based on clinical experience in the treatment of epilepsy for more than 20 years in Japan, ZNS is a relatively safe and well tolerated drug.

\section{References}

Asanuma, M., Miyazaki, I., Diaz-Corrales, F. J., Kimoto, N., Kikkawa, Y., Takeshima, M., Miyoshi, K. \& Murata, M. (2010). Neuroprotective effects of zonisamide target astrocyte. Ann Neurol Vol. 67, pp. 239-249, ISSN 1531-8249

Asanuma, M., Miyazaki, I., Diaz-Corrales, F. J., Miyoshi, K., Ogawa, N. \& Murata, M. (2008). Preventing effects of a novel anti-parkinsonian agent zonisamide on dopamine quinone formation. Neurosci Res Vol. 60, pp. 106-113, ISSN 0168-0102 
Asanuma, M., Miyazaki, I. \& Ogawa, N. (2003). Dopamine- or L-DOPA-induced neurotoxicity: the role of dopamine quinone formation and tyrosinase in a model of Parkinson's disease. Neurotox Res Vol. 5, pp. 165-176, ISSN 1029-8428

Bermejo, P. E. (2007). Zonisamide in patients with essential tremor and Parkinson's disease. Mov Disord Vol. 22, pp. 2137-2138, ISSN 0885-3185

Berridge, M. J. (1998). Neuronal calcium signaling. Neuron Vol. 21, pp. 13-26,

Brodie, M. J. (2004). Zonisamide clinical trials: European experience. Seizure Vol. 13 Suppl 1, pp. S66-72,

Casini, A., Abbate, F., Scozzafava, A. \& Supuran, C. T. (2003). Carbonic anhydrase inhibitors: X-ray crystallographic structure of the adduct of human isozyme II with a bis-sulfonamide-two heads are better than one? Bioorg Med Chem Lett Vol. 13, pp. 2759-2763, ISSN 0960-894X

Chinta, S. J., Kumar, M. J., Hsu, M., Rajagopalan, S., Kaur, D., Rane, A., Nicholls, D. G., Choi, J. \& Andersen, J. K. (2007). Inducible alterations of glutathione levels in adult dopaminergic midbrain neurons result in nigrostriatal degeneration. J Neurosci Vol. 27, pp. 13997-14006, ISSN 1529-2401

DeLong, M. R. (1990). Primate models of movement disorders of basal ganglia origin. Trends Neurosci Vol. 13, pp. 281-285, ISSN 0166-2236

Ge, S., Goh, E. L., Sailor, K. A., Kitabatake, Y., Ming, G. L. \& Song, H. (2006). GABA regulates synaptic integration of newly generated neurons in the adult brain. Nature Vol. 439, pp. 589-593, ISSN 1476-4687

Ge, S., Pradhan, D. A., Ming, G. L. \& Song, H. (2007). GABA sets the tempo for activitydependent adult neurogenesis. Trends Neurosci Vol. 30, pp. 1-8, ISSN 0166-2236

Ghaemi, S. N., Shirzadi, A. A., Klugman, J., Berv, D. A., Pardo, T. B. \& Filkowski, M. M. (2008). Is adjunctive open-label zonisamide effective for bipolar disorder? J Affect Disord Vol. 105, pp. 311-314, ISSN 0165-0327

Ghaemi, S. N., Zablotsky, B., Filkowski, M. M., Dunn, R. T., Pardo, T. B., Isenstein, E. \& Baldassano, C. F. (2006). An open prospective study of zonisamide in acute bipolar depression. J Clin Psychopharmacol Vol. 26, pp. 385-388, ISSN 0271-0749

Gibb, W. R. (1991). Neuropathology of the substantia nigra. Eur Neurol Vol. 31 Suppl 1, pp. 48-59, ISSN 0014-3022

Hauber, W. (1998). Involvement of basal ganglia transmitter systems in movement initiation. Prog Neurobiol Vol. 56, pp. 507-540, ISSN 0301-0082

Hayakawa, T., Higuchi, Y., Nigami, H. \& Hattori, H. (1994). Zonisamide reduces hypoxicischemic brain damage in neonatal rats irrespective of its anticonvulsive effect. Eur J Pharmacol Vol. 257, pp. 131-136, ISSN 0014-2999

Hille, C. J., Fox, S. H., Maneuf, Y. P., Crossman, A. R. \& Brotchie, J. M. (2001). Antiparkinsonian action of a delta opioid agonist in rodent and primate models of Parkinson's disease. Exp Neurol Vol. 172, pp. 189-198, ISSN 0014-4886

Hirose, S., Okada, M., Kaneko, S. \& Mitsudome, A. (2000). Are some idiopathic epilepsies disorders of ion channels?: A working hypothesis. Epilepsy Res Vol. 41, pp. 191-204, ISSN 0920-1211

Kanba, S., Yagi, G., Kamijima, K., Suzuki, T., Tajima, O., Otaki, J., Arata, E., Koshikawa, H., Nibuya, M., Kinoshita, N. \& et al. (1994). The first open study of zonisamide, a novel anticonvulsant, shows efficacy in mania. Prog Neuropsychopharmacol Biol Psychiatry Vol. 18, pp. 707-715, 
Karceski, S., Morrell, M. J. \& Carpenter, D. (2005). Treatment of epilepsy in adults: expert opinion, 2005. Epilepsy Behav Vol. 7 Suppl 1, pp. S1-64; quiz S65-67, ISSN 1525-5050

Kawata, Y., Okada, M., Murakami, T., Mizuno, K., Wada, K., Kondo, T. \& Kaneko, S. (1999). Effects of zonisamide on $\mathrm{K}+$ and $\mathrm{Ca} 2+$ evoked release of monoamine as well as $\mathrm{K}+$ evoked intracellular Ca2+ mobilization in rat hippocampus. Epilepsy Res Vol. 35, pp. 173-182, ISSN 0920-1211

Kito, M., Maehara, M. \& Watanabe, K. (1996). Mechanisms of T-type calcium channel blockade by zonisamide. Seizure Vol. 5, pp. 115-119, ISSN 1059-1311

Komatsu, M., Hiramatsu, M. \& Willmore, L. J. (2000). Zonisamide reduces the increase in 8hydroxy-2'-deoxyguanosine levels formed during iron-induced epileptogenesis in the brains of rats. Epilepsia Vol. 41, pp. 1091-1094, ISSN 0013-9580

Leniger, T., Thone, J. \& Wiemann, M. (2004). Topiramate modulates $\mathrm{pH}$ of hippocampal CA3 neurons by combined effects on carbonic anhydrase and Cl-/HCO3exchange. Br J Pharmacol Vol. 142, pp. 831-842, ISSN 0007-1188

Leppik, I. E. (2004). Zonisamide: chemistry, mechanism of action, and pharmacokinetics. Seizure Vol. 13 Suppl 1, pp. S5-9; discussion S10, ISSN 1059-1311

Macdonald, R., 2002. Zonisamide, Mechanisms of action. In: Mattson RH, M. B., Perucca E, (Ed), Antiepileptic drugs 5th edn. Lippincott Williams \& Wilkins, Philadelphia, pp. 867-872.

Maneuf, Y. P., Mitchell, I. J., Crossman, A. R. \& Brotchie, J. M. (1994). On the role of enkephalin cotransmission in the GABAergic striatal efferents to the globus pallidus. Exp Neurol Vol. 125, pp. 65-71, ISSN 0014-4886

Masuda, Y. \& Karasawa, T. (1993). Inhibitory effect of zonisamide on human carbonic anhydrase in vitro. Arzneimittelforschung Vol. 43, pp. 416-418, ISSN 0004-4172

Matsumoto, M. \& Nagata, E. (1999). Type 1 inositol 1,4,5-trisphosphate receptor knock-out mice: their phenotypes and their meaning in neuroscience and clinical practice. $J$ Mol Med Vol. 77, pp. 406-411,

Matsumoto, M., Nakagawa, T., Inoue, T., Nagata, E., Tanaka, K., Takano, H., Minowa, O., Kuno, J., Sakakibara, S., Yamada, M., Yoneshima, H., Miyawaki, A., Fukuuchi, Y., Furuichi, T., Okano, H., Mikoshiba, K. \& Noda, T. (1996). Ataxia and epileptic seizures in mice lacking type 1 inositol 1,4,5-trisphosphate receptor. Nature Vol. 379, pp. 168-171,

McElroy, S. L., Suppes, T., Keck, P. E., Jr., Black, D., Frye, M. A., Altshuler, L. L., Nolen, W. A., Kupka, R. W., Leverich, G. S., Walden, J., Grunze, H. \& Post, R. M. (2005). Openlabel adjunctive zonisamide in the treatment of bipolar disorders: a prospective trial. J Clin Psychiatry Vol. 66, pp. 617-624,

Mimaki, T., Suzuki, Y., Tagawa, T., Tanaka, J., Itoh, N. \& Yabuuchi, H. (1988). [3H]zonisamide binding in rat brain. Jpn J Psychiatry Neurol Vol. 42, pp. 640-642, ISSN 0912-2036

Mori, A., Noda, Y. \& Packer, L. (1998). The anticonvulsant zonisamide scavenges free radicals. Epilepsy Res Vol. 30, pp. 153-158, ISSN 0920-1211

Mori, F., Okada, M., Tomiyama, M., Kaneko, S. \& Wakabayashi, K. (2005). Effects of ryanodine receptor activation on neurotransmitter release and neuronal cell death following kainic acid-induced status epilepticus. Epilepsy Res Vol. 65, pp. 59-70. ISSN 0920-1211 
Murakami, T., Okada, M., Kawata, Y., Zhu, G., Kamata, A. \& Kaneko, S. (2001). Determination of effects of antiepileptic drugs on SNAREs-mediated hippocampal monoamine release using in vivo microdialysis. Br J Pharmacol Vol. 134, pp. 507520, ISSN 0007-1188

Murata, M. (2004). Novel therapeutic effects of the anti-convulsant, zonisamide, on Parkinson's disease. Curr Pharm Des Vol. 10, pp. 687-693,

Murata, M., Hasegawa, K. \& Kanazawa, I. (2007). Zonisamide improves motor function in Parkinson disease: a randomized, double-blind study. Neurology Vol. 68, pp. 45-50,

Murata, M., Horiuchi, E. \& Kanazawa, I. (2001). Zonisamide has beneficial effects on Parkinson's disease patients. Neurosci Res Vol. 41, pp. 397-399,

Noda, Y., Mori, A. \& Packer, L. (1999). Zonisamide inhibits nitric oxide synthase activity induced by N-methyl-D-aspartate and buthionine sulfoximine in the rat hippocampus. Res Commun Mol Pathol Pharmacol Vol. 105, pp. 23-33, ISSN 1078-0297

Obrenovitch, T. P., Richards, D. A., Sarna, G. S. \& Symon, L. (1993). Combined intracerebral microdialysis and electrophysiological recording: methodology and applications. J Neurosci Methods Vol. 47, pp. 139-145, ISSN 0165-0270

Obrenovitch, T. P., Urenjak, J. \& Zilkha, E. (1996). Evidence disputing the link between seizure activity and high extracellular glutamate. J Neurochem Vol. 66, pp. 24462454, ISSN 0022-3042

Ogawa, N., Asanuma, M., Miyazaki, I., Diaz-Corrales, F. J. \& Miyoshi, K. (2005). L-DOPA treatment from the viewpoint of neuroprotection. Possible mechanism of specific and progressive dopaminergic neuronal death in Parkinson's disease. J Neurol Vol. 252 Suppl 4, pp. IV23-IV31, ISSN 0340-5354

Okada, M., Hirano, T., Kawata, Y., Murakami, T., Wada, K., Mizuno, K., Kondo, T. \& Kaneko, S. (1999). Biphasic effects of zonisamide on serotonergic system in rat hippocampus. Epilepsy Res Vol. 34, pp. 187-197,

Okada, M., Kaneko, S., Hirano, T., Ishida, M., Kondo, T., Otani, K. \& Fukushima, Y. (1992). Effects of zonisamide on extracellular levels of monoamine and its metabolite, and on Ca2+ dependent dopamine release. Epilepsy Res Vol. 13, pp. 113-119, ISSN 09201211

Okada, M., Kaneko, S., Hirano, T., Mizuno, K., Kondo, T., Otani, K. \& Fukushima, Y. (1995). Effects of zonisamide on dopaminergic system. Epilepsy Res Vol. 22, pp. 193-205,

Okada, M., Kawata, Y., Mizuno, K., Wada, K., Kondo, T. \& Kaneko, S. (1998). Interaction between $\mathrm{Ca}^{2+}, \mathrm{K}^{+}$, carbamazepine and zonisamide on hippocampal extracellular glutamate monitored with a microdialysis electrode. Br J Pharmacol Vol. 124, pp. ISSN 1277-1285

Okada, M., Yoshida, S., Zhu, G., Hirose, S. \& Kaneko, S. (2005). Biphasic actions of topiramate on monoamine exocytosis associated with both soluble Nethylmaleimide-sensitive factor attachment protein receptors and $\mathrm{Ca}(2+)$-induced $\mathrm{Ca}(2+)$-releasing systems. Neuroscience Vol. 134, pp. 233-246, ISSN 0306-4522

Okada, M., Zhu, G., Hirose, S., Ito, K. I., Murakami, T., Wakui, M. \& Kaneko, S. (2003). Agedependent modulation of hippocampal excitability by KCNQ-channels. Epilepsy Res Vol. 53, pp. 81-94, ISSN 0920-1211

Okada, M., Zhu, G., Yoshida, S., Kanai, K., Hirose, S. \& Kaneko, S. (2002). Exocytosis mechanism as a new targeting site for mechanisms of action of antiepileptic drugs. Life Sci Vol. 72, pp. 465-473, ISSN 0024-3205 
Okada, M., Zhu, G., Yoshida, S. \& Kaneko, S. (2010). Validation criteria for genetic animal models of epilepsy. Epilepsy \& Seizure Vol. 3, pp. 109-120,

Owen, A. J., Ijaz, S., Miyashita, H., Wishart, T., Howlett, W. \& Shuaib, A. (1997). Zonisamide as a neuroprotective agent in an adult gerbil model of global forebrain ischemia: a histological, in vivo microdialysis and behavioral study. Brain Res Vol. 770, pp. 115122, ISSN 0006-8993

Pal, S., Sun, D., Limbrick, D., Rafiq, A. \& DeLorenzo, R. J. (2001). Epileptogenesis induces long-term alterations in intracellular calcium release and sequestration mechanisms in the hippocampal neuronal culture model of epilepsy. Cell Calcium Vol. 30, pp. 285-296, ISSN 0143-4160

Pelletier, M. R., Wadia, J. S., Mills, L. R. \& Carlen, P. L. (1999). Seizure-induced cell death produced by repeated tetanic stimulation in vitro: possible role of endoplasmic reticulum calcium stores. J Neurophysiol Vol. 81, pp. 3054-3064, ISSN 0022-3077

Perez-Reyes, E. (2003). Molecular physiology of low-voltage-activated t-type calcium channels. Physiol Rev Vol. 83, pp. 117-161, ISSN 0031-9333

Rock, D. M., Macdonald, R. L. \& Taylor, C. P. (1989). Blockade of sustained repetitive action potentials in cultured spinal cord neurons by zonisamide (AD 810, CI 912), a novel anticonvulsant. Epilepsy Res Vol. 3, pp. 138-143, ISSN 0920-1211

Rogawski, M. A. \& Loscher, W. (2004a). The neurobiology of antiepileptic drugs. Nat Rev Neurosci Vol. 5, pp. 553-564, ISSN 1471-003X

Rogawski, M. A. \& Loscher, W. (2004b). The neurobiology of antiepileptic drugs for the treatment of nonepileptic conditions. Nat Med Vol. 10, pp. 685-692, ISSN 1078-8956

Rogawski, M. A. \& Porter, R. J. (1990). Antiepileptic drugs: pharmacological mechanisms and clinical efficacy with consideration of promising developmental stage compounds. Pharmacol Rev Vol. 42, pp. 223-286, ISSN 0031-6997

Rossier, M. F., Burnay, M. M., Vallotton, M. B. \& Capponi, A. M. (1996). Distinct functions of T- and L-type calcium channels during activation of bovine adrenal glomerulosa cells. Endocrinology Vol. 137, pp. 4817-4826, ISSN 0013-7227

Schauf, C. L. (1987). Zonisamide enhances slow sodium inactivation in Myxicola. Brain Res Vol. 413, pp. 185-188, ISSN 0006-8993

Seino, M. (2004). Review of zonisamide development in Japan. Seizure Vol. 13 Suppl 1, pp. S2-4,

Seino, M. \& Leppik, I., 2007. Zonisamide. In: Engel, J., Jr. and Pedley, TA., , (Ed), Epilepsy: a comprehensive text book Lippincott Williams \& Wilkins, Philadelphia, pp. 16951701.

Seino, M., Ohkuma, T. \& Mlyasaka, M. (1988). Efficacy evaluation of AD-810 (zonisamide), results of a duble blind comparison with carbamazepine (CBZ). J Clin Exp Med Vol. 44, pp.

Shih, A. Y., Erb, H., Sun, X., Toda, S., Kalivas, P. W. \& Murphy, T. H. (2006). Cystine/glutamate exchange modulates glutathione supply for neuroprotection from oxidative stress and cell proliferation. J Neurosci Vol. 26, pp. ISSN 1051410523,

Sills, G. J., Leach, J. P., Kilpatrick, W. S., Fraser, C. M., Thompson, G. G. \& Brodie, M. J. (2000). Concentration-effect studies with topiramate on selected enzymes and intermediates of the GABA shunt. Epilepsia Vol. 41 Suppl 1, pp. S30-34, ISSN 00139580 
Solano, R. M., Casarejos, M. J., Menendez-Cuervo, J., Rodriguez-Navarro, J. A., Garcia de Yebenes, J. \& Mena, M. A. (2008). Glial dysfunction in parkin null mice: effects of aging. J Neurosci Vol. 28, pp. 598-611, ISSN 1529-2401

Staley, K. J., Soldo, B. L. \& Proctor, W. R. (1995). Ionic mechanisms of neuronal excitation by inhibitory GABAA receptors. Science Vol. 269, pp. 977-981, ISSN 0036-8075

Sudha, K., Rao, A. V. \& Rao, A. (2001). Oxidative stress and antioxidants in epilepsy. Clin Chim Acta Vol. 303, pp. 19-24, ISSN 0009-8981

Sulzer, D., Bogulavsky, J., Larsen, K. E., Behr, G., Karatekin, E., Kleinman, M. H., Turro, N., Krantz, D., Edwards, R. H., Greene, L. A. \& Zecca, L. (2000). Neuromelanin biosynthesis is driven by excess cytosolic catecholamines not accumulated by synaptic vesicles. Proc Natl Acad Sci U S A Vol. 97, pp. 11869-11874, ISSN 0027-8424

Supuran, C. T. (2008). Carbonic anhydrases: novel therapeutic applications for inhibitors and activators. Nat Rev Drug Discov Vol. 7, pp. 168-181, ISSN 1474-1784

Suzuki, S., Kawakami, K., Nishimura, S., Watanabe, Y., Yagi, K., Seino, M. \& Miyamoto, K. (1992). Zonisamide blocks T-type calcium channel in cultured neurons of rat cerebral cortex. Epilepsy Res Vol. 12, pp. 21-27, ISSN 0920-1211

Tokumaru, J., Ueda, Y., Yokoyama, H., Nakajima, A., Doi, T., Mitsuyama, Y., OhyaNishiguchi, H. \& Kamada, H. (2000). In vivo evaluation of hippocampal antioxidant ability of zonisamide in rats. Neurochem Res Vol. 25, pp. 1107-1111, ISSN 0364-3190

Tse, D. C., McCreery, R. L. \& Adams, R. N. (1976). Potential oxidative pathways of brain catecholamines. J Med Chem Vol. 19, pp. 37-40, ISSN 0022-2623

Ueda, Y., Doi, T., Tokumaru, J., Nakajima, A. \& Nagatomo, K. (2005). In vivo evaluation of the effect of zonisamide on the hippocampal redox state during kainic acid-induced seizure status in rats. Neurochem Res Vol. 30, pp. 1117-1121, ISSN 0364-3190

Ueda, Y., Doi, T., Tokumaru, J. \& Willmore, L. J. (2003). Effect of zonisamide on molecular regulation of glutamate and GABA transporter proteins during epileptogenesis in rats with hippocampal seizures. Brain Res Mol Brain Res Vol. 116, pp. 1-6, ISSN 0169-328X

Wang, X. F. \& Cynader, M. S. (2000). Astrocytes provide cysteine to neurons by releasing glutathione. J Neurochem Vol. 74, pp. 1434-1442, ISSN 0022-3042

White, H. S. (1999). Comparative anticonvulsant and mechanistic profile of the established and newer antiepileptic drugs. Epilepsia Vol. 40 Suppl 5, pp. S2-10, ISSN 0013-9580

Willmore, L. J. (2004). Zonisamide overview of the United States experience. Seizure Vol. 13 Suppl 1, pp. S57-58,

Yamamura, S., Hamaguchi, T., Ohoyama, K., Sugiura, Y., Suzuki, D., Kanehara, S., Nakagawa, M., Motomura, E., Matsumoto, T., Tanii, H., Shiroyama, T. \& Okada, M. (2009a). Topiramate and zonisamide prevent paradoxical intoxication induced by carbamazepine and phenytoin. Epilepsy Res Vol. 84, pp. 172-186, ISSN 1872-6844

Yamamura, S., Ohoyama, K., Nagase, H. \& Okada, M. (2009b). Zonisamide enhances delta receptor-associated neurotransmitter release in striato-pallidal pathway. Neuropharmacology Vol. 57, pp. 322-331, ISSN 1873-7064

Yamamura, S., Saito, H., Suzuki, N., Kashimoto, S., Hamaguchi, T., Ohoyama, K., Suzuki, D., Kanehara, S., Nakagawa, M., Shiroyama, T. \& Okada, M. (2009c). Effects of zonisamide on neurotransmitter release associated with inositol triphosphate receptors. Neurosci Lett Vol. 454, pp. 91-96, ISSN 1872-7972 
Yoshida, S., Okada, M., Zhu, G. \& Kaneko, S. (2005). Effects of zonisamide on neurotransmitter exocytosis associated with ryanodine receptors. Epilepsy Res Vol. 67, pp. 153-162, ISSN 0920-1211

Zhang, X., Velumian, A. A., Jones, O. T. \& Carlen, P. L. (2000). Modulation of high-voltageactivated calcium channels in dentate granule cells by topiramate. Epilepsia Vol. 41 Suppl 1, pp. S52-60, ISSN 0013-9580

Zhu, G., Okada, M., Yoshida, S., Ueno, S., Mori, F., Takahara, T., Saito, R., Miura, Y., Kishi, A., Tomiyama, M., Sato, A., Kojima, T., Fukuma, G., Wakabayashi, K., Hase, K., Ohno, H., Kijima, H., Takano, Y., Mitsudome, A., Kaneko, S. \& Hirose, S. (2008). Rats harboring S284L Chrna4 mutation show attenuation of synaptic and extrasynaptic GABAergic transmission and exhibit the nocturnal frontal lobe epilepsy phenotype. J Neurosci Vol. 28, pp. 12465-12476, ISSN 1529-2401

Zilkha, E., Obrenovitch, T. P., Koshy, A., Kusakabe, H. \& Bennetto, H. P. (1995). Extracellular glutamate: on-line monitoring using microdialysis coupled to enzyme-amperometric analysis. J Neurosci Methods Vol. 60, pp. 1-9, ISSN 0165-0270 


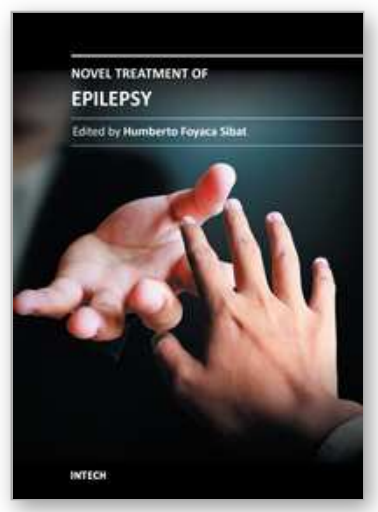

\author{
Novel Treatment of Epilepsy \\ Edited by Prof. Humberto Foyaca-Sibat
}

ISBN 978-953-307-667-6

Hard cover, 326 pages

Publisher InTech

Published online 22, September, 2011

Published in print edition September, 2011

Epilepsy continues to be a major health problem throughout the planet, affecting millions of people, mainly in developing countries where parasitic zoonoses are more common and cysticercosis, as a leading cause, is endemic. There is epidemiological evidence for an increasing prevalence of epilepsy throughout the world, and evidence of increasing morbidity and mortality in many countries as a consequence of higher incidence of infectious diseases, head injury and stroke. We decided to edit this book because we identified another way to approach this problem, covering aspects of the treatment of epilepsy based on the most recent technological results â€œin vitroâ€ from developed countries, and the basic treatment of epilepsy at the primary care level in rural areas of South Africa. Therefore, apart from the classic issues that cannot be missing in any book about epilepsy, we introduced novel aspects related with epilepsy and neurocysticercosis, as a leading cause of epilepsy in developing countries. Many experts from the field of epilepsy worked hard on this publication to provide valuable updated information about the treatment of epilepsy and other related problems.

\title{
How to reference
}

In order to correctly reference this scholarly work, feel free to copy and paste the following:

Motohiro Okada and Sunao Kaneko (2011). Different Mechanisms Underlying the Antiepileptic and Antiparkinsonian Effects of Zonisamide, Novel Treatment of Epilepsy, Prof. Humberto Foyaca-Sibat (Ed.), ISBN: 978-953-307-667-6, InTech, Available from: http://www.intechopen.com/books/novel-treatment-ofepilepsy/different-mechanisms-underlying-the-antiepileptic-and-antiparkinsonian-effects-of-zonisamide

\section{INTECH}

open science | open minds

\section{InTech Europe}

University Campus STeP Ri

Slavka Krautzeka 83/A

51000 Rijeka, Croatia

Phone: +385 (51) 770447

Fax: +385 (51) 686166

www.intechopen.com

\section{InTech China}

Unit 405, Office Block, Hotel Equatorial Shanghai

No.65, Yan An Road (West), Shanghai, 200040, China

中国上海市延安西路65号上海国际贵都大饭店办公楼 405 单元

Phone: +86-21-62489820

Fax: $+86-21-62489821$ 
(C) 2011 The Author(s). Licensee IntechOpen. This chapter is distributed under the terms of the Creative Commons Attribution-NonCommercialShareAlike-3.0 License, which permits use, distribution and reproduction for non-commercial purposes, provided the original is properly cited and derivative works building on this content are distributed under the same license. 